\title{
Cultivo de amendoim em função da adubação e do espaçamento entre plantas em sistema de sequeiro e irrigação complementar
}

Antonio Alves Pinto ${ }^{1}$, Leandro Alves Pinto ${ }^{2}$, Laudeline Dantas Santana ${ }^{2}$, Felipe Thomaz da Camara ${ }^{2}$, Luis Fernando Vieira da Silva ${ }^{1}$

${ }^{1}$ Universidade Estadual Paulista - UNESP, SP. ${ }^{2}$ Universidade Federal do Cariri, CE. E-mail: antonioalvesunesp@gmail.com

\section{Resumo}

No Nordeste o amendoim é cultivada quase que exclusivamente por produtores da agricultura familiar, com baixos níveis tecnológico, além do baixo uso de insumos, essenciais para garantir melhores produtividades. O presente trabalho objetivou avaliar o desempenho e produtividade do amendoim submetido a doses de adubação e espaçamentos entre plantas, em sistema de sequeiro e com irrigação complementar. O experimento foi realizado na Universidade Federal do Cariri. Foram conduzidos dois experimentos um em sistema de sequeiro sem uso de irrigação e outro com irrigação por gotejo suplementar, em blocos ao acaso com esquema de parcelas subdivididas, com quatro repetições. As parcelas foram quatro doses de adubação na semeadura $(0,50,100$ e $150 \%)$ e as subparcelas dois espaçamentos entre plantas $(10$ e $20 \mathrm{~cm}$ ). A cultivar de amendoim utilizada foi a BRS151L7. A semeadura foi realizada manualmente, depositando-se 5 e 10 sementes $\mathrm{m}^{-1}$, conforme o espaçamento entre plantas. A colheita foi realizada manualmente aos 90 dias após a semeadura. As variáveis população inicial e final apresentaram significância $(p<0,01)$ para os espaçamentos entre plantas no sistema de sequeiro e com irrigação complementar. A massa de plantas e de grãos por planta apresentaram diferença significativa a $1 \%$ no espaçamento para o sistema com irrigação. No fator adubação, a altura de plantas foi a única variável que apresentou significância $(p<0,05)$. A aplicação de $80 \%$ da dose recomendada de fósforo e potássio é suficiente para suprir a necessidade da cultura. $O$ espaçamento de $10 \mathrm{~cm}$ entre plantas foi o melhor para acultura. O uso de irrigação complementar aumentou em mais de $300 \%$ a produtividade de vagens e de grãos do amendoim.

Palavras-chave: Arachis hypogaea L.; doses; gotejo; potássio.

Peanut cultivation in function of fertilization and the spacing between plants in the rainfed system and supplementary irrigation system

\begin{abstract}
In the rigion Nordeste, the peanut is cultivated almost exclusively by family agriculture producers with low technological levels, in addition to the low use of inputs, essential to ensure better productivity. Objective to evaluate the performance and productivity of peanut subjected to doses of fertilization and spacing between plants, in the rainfed system and irrigation system. The experiment was conducted at the Federal University of cariri. Two experiments were conducted in randomized blocks in parcel scheme subdivided, with four replicates.The plots were four doses of fertilization on sowing $(0,50,100$ and $150 \%)$ and the subplots two spaces between plants $(10$ and $20 \mathrm{~cm})$. The peanut cultivar used was the BRS151L7. Sowing was carried out manually, depositing-if 5 and 10 as the spacing between plants. The harvest was carried out manually to 90 days after sowing. The variables population initial and final population showed significant ( $p$ $<0.01$ ) to the spacing between plants in system rainfed and irrigation system. The mass of plants and grains per plant showed significant difference to $1 \%$ in the spacing for the irrigation system. In the fertilizing factor, the height of plants was the only variable that showed significance $(p<0.05)$. The application of $80 \%$ of the recommended dose of phosphorus and potassium is enough to meet the need of culture. The $10 \mathrm{~cm}$ spacing between plants was the best for culture. The use of supplemental irrigation has increased by more than $300 \%$ the productivity of grain and peanut pods.
\end{abstract}

Keywords: Arachis hypogaea L.; doses; drip; potassium. 


\section{Introdução}

O amendoim (Arachis hypogaea, L.) apresenta importante papel no mercado alimentício em função do uso na produção de óleos, pastas, suplementos alimentares, e até mesmo para o consumo "in natura", tornando-a uma das oleaginosas mais cultivadas no mundo (COSTA et al., 2017).

No Nordeste, as maiores áreas cultivadas concentram-se principalmente nos estados da Bahia, Sergipe, Paraíba e Ceará, com o Estado de Sergipe destacando-se como o maior produtor, responsável por cerca de $40 \%$ da produção da Região Nordeste (CONAB, 2017).

$\mathrm{Na}$ Região Nordeste é cultivado principalmente por produtores da agricultura familiar, com diversos níveis tecnológicos, realizando na maioria das vezes o manejo de forma manual, além do baixo uso de insumos que são essenciais para garantir melhores produtividades (COSTA et al., 2017). A adubação mineral no cultivo do amendoim apresenta papel importante no desenvolvimento e no aumento da produtividade (COSTA et al., 2017). Porém, os trabalhos desenvolvidos com a cultura não apresentam resultados conclusivos sobre as melhores doses em relação à adubação nas condições de sequeiro e irrigado (SOUZA et al., 2012; COSTA et al., 2017; MENEGHETTE et al., 2017).

Segundo Sousa et al. (2013), a adubação com fertilizantes à base de potássio favorece o aumento da produtividade da cultura do amendoim, por ser um nutriente essencial para o crescimento e desenvolvimento dos vegetais, enquanto a deficiência pode provocar a formação de vagens com poucas sementes (CORREIA et al., 2012). O fósforo por sua vez, promove aumento no desenvolvimento das plantas de amendoim, além de afetar o enchimento das vagens (SANTOS et al., 2010).

De forma geral, a adubação situa-se como importante fator no planejamento da produção, porém, a escolha do espaçamento adequado para otimizar o uso da área de produção sem causar adensamento excessivo é outro fator a ser considerado. Conforme Peixoto et al. (2008), a utilização do espaçamento adequado interfere na uniformização da maturação, manejo de plantas daninhas e contribui com a maximização da produtividade.
O espaçamento apresenta-se como uma importante estratégia de produção por proporcionar melhor aproveitamento de fatores que estão diretamente relacionados com a produção do amendoim como água, luz e nutrientes (HEID et al., 2016).

O consumo de água na cultura do amendoim destaca-se por ser fator limitante no cultivo, principalmente em regiões com chuvas irregulares, como o nordeste do Brasil. A necessidade hídrica da cultura divide-se em três fases distintas, na primeira o consumo é relativamente baixo (emergência até a floração); na segunda o consumo hídrico aumenta (floração à formação das vagens); já a terceira apresenta maior consumo (formação das vagens até a maturação das sementes), necessitando de aproximadamente $650 \mathrm{~mm}$ por ciclo para suprir a necessidade da cultura, garantindo elevada produtividade (DIAS et al. 2019).

Em virtude da escassez de trabalhos que visem determinar a dose ideal da adubação, juntamente com o espaçamento adequado para as condições climáticas da região nordeste, objetivou-se avaliar no presente trabalho o desempenho e produtividade da cultivar de amendoim BRS151L7, submetida a doses de adubação de semeadura e espaçamentos entre plantas, em sistema de sequeiro e com irrigação complementar.

\section{Material e Métodos}

O trabalho foi desenvolvido na área experimental do Centro de Ciências Agrárias e da Biodiversidade, da Universidade Federal do Cariri (UFCA), no município de Crato, Ceará, com as coordenadas geográficas $7^{\circ} 14^{\prime} 49^{\prime \prime} \mathrm{S}, 39^{\circ} 22^{\prime} 05^{\prime \prime} \mathrm{W}$ e 413 metros de altitude, no período de março a junho de 2017. O clima é caracterizado como tropical úmido com estação seca, correspondente à classificação Aw de Köppen (PINTO et al., 2017), com regime pluviométrico de 700 a $1.000 \mathrm{~mm}$ $a^{-1} o^{-}$. A temperatura média anual é de $27^{\circ} \mathrm{C}$.

A distribuição das chuvas no período de execução do experimento foi mensurada por pluviômetro instalado ao lado da área, com os dados expressos na Figura 1. A precipitação pluviométrica foi de $296 \mathrm{~mm}$ durante todo o ciclo da cultura. 
Figura 1. Dados de precipitação de março a maio de 2017 período da semeadura ao início da maturação, Crato, Ceará.

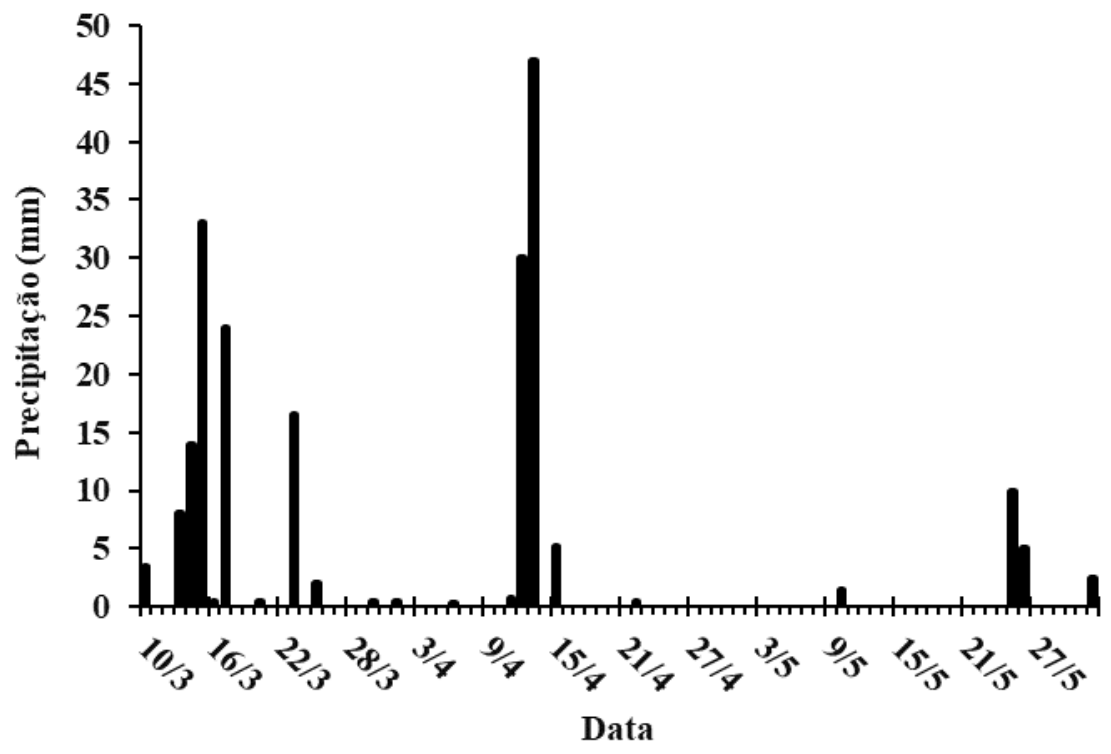

Fonte: autor

O solo da área experimental é classificado como Argissolo Vermelho Amarelo, de textura arenosa, contendo na profundidade de $0-20 \mathrm{~cm}$ teores de 873; 33 e $94 \mathrm{~g} \mathrm{~kg}^{-1}$ de areia, silte e argila, respectivamente (SILVA et al., 2017). Os resultados obtidos com a análise química do solo de $0-20 \mathrm{~cm}$ de profundidade foram: $\mathrm{pH}(1: 2,5$ $\mathrm{H}_{2} \mathrm{O}$ ): 5,9; $\mathrm{P}\left(\right.$ melich $\left.^{-1}\right)=5,7 \mathrm{mg} \mathrm{dm}^{-3} ; \mathrm{K}=1,90$ $\mathrm{mmol}_{\mathrm{c}} \mathrm{dm}^{-3} ; \mathrm{Ca}=15,3 \mathrm{mmol}_{\mathrm{c}} \mathrm{dm}^{-3} ; \mathrm{Mg}=5,0$ $\mathrm{mmol}_{\mathrm{c}} \mathrm{dm}^{-3} ; \mathrm{Al}^{3+}=0,0 \mathrm{mmol}_{\mathrm{c}} \mathrm{dm}^{-3} ; \mathrm{H}+\mathrm{Al}=10,4$ $\mathrm{mmol}_{\mathrm{c}} \mathrm{dm}^{-3} ; \mathrm{CTC}=33,0 \mathrm{mmol}_{\mathrm{c}} \mathrm{dm}^{-3} \mathrm{e} \mathrm{V} \%=68,5$.

Foram conduzidos dois experimentos simultaneamente localizados um ao lado do outro, sendo um em sistema de sequeiro sem uso de irrigação e outro com irrigação por gotejo suplementar com fitas gotejadoras, visando suprir a demanda hídrica da cultura do amendoim devido à distribuição irregular das chuvas na região.

Ambos os experimentos foram conduzidos em blocos ao acaso em esquema de parcela subdividida, com quatro repetições. As parcelas foram constituídas pelas doses de adubação de semeadura $(0,50,100$ e $150 \%$ da dose recomendada) e as subparcelas foram dois espaçamentos entre plantas $(10$ e $20 \mathrm{~cm})$. As subparcelas constaram de quatro fileiras duplas com três metros de comprimento e com espaçamento de 0,6 m entre as duplas e de 0,3 m entre as fileiras simples. Foi considerado como área útil as duas fileiras centrais com um metro de comprimento.
A cultivar de amendoim utilizada foi a BRS151L7, desenvolvida pela Embrapa para a região nordeste, de porte ereto e ciclo de 90 dias.

A dose recomendada para a adubação de semeadura no amendoim foi obtida com base na análise de solo e nas exigências da cultura, utilizando-se a recomendação feita pela Embrapa (2014). Utilizou-se como dose ideal (100\%) as quantias de $80 \mathrm{~kg} \mathrm{ha}^{-1}$ de $\mathrm{P}_{2} \mathrm{O}_{5}\left(444 \mathrm{~kg} \mathrm{ha}^{-1}\right.$ de superfosfato simples) e $40 \mathrm{~kg} \mathrm{ha}^{-1}$ de $\mathrm{K}_{2} \mathrm{O}(67 \mathrm{~kg}$ $\mathrm{ha}^{-1}$ de cloreto de potássio). As demais doses estudadas foram variações proporcionais a dose recomendada. Não foi realizada adubação nitrogenada em virtude de ser uma leguminosa que realiza simbiose com bactérias do gênero Rhizobium.

Para o experimento com irrigação suplementar por gotejo, foram utilizadas fitas gotejadoras localizadas entre as fileiras nas fileiras duplas, onde cada mangueira gotejadora irrigava duas fileiras de amendoim. Nos dias em que não ocorreu precipitação atmosférica foi utilizada uma lâmina de irrigação diária de 7,5 $\mathrm{mm}$ conforme recomendado pela Embrapa.

A semeadura e adubação foram realizadas manualmente no dia 10 de março de 2017, depositando-se 5 e 10 sementes $\mathrm{m}^{-1}$ para o espaçamento de 20 e $10 \mathrm{~cm}$ entre plantas, respectivamente. Foram realizados todos os tratos culturais demandados pela cultura como capinas manuais e a amontoa no florescimento, prática indispensável para o amendoim de porte 
ereto. A colheita foi realizada em junho de 2017, com 90 dias após a semeadura (DAS), mantendose as plantas com as vagens voltadas para cima por cinco dias no campo para secagem.

Durante a condução do estudo, foi avaliada a população inicial, (contagem da quantidade de plantas emergidas em um metro de fileira, com os dados sendo convertidos para plantas $\left.h^{-1}\right)$, aos 21 dias após a semeadura (DAS). Pelo mesmo método da população inicial foi realizada a população final na colheita.

Após a colheita foram avaliadas a altura das plantas (diferença entre a superfície do solo e o ápice da planta), número e massa de vagens e de grãos por planta (obtida a partir da contagem e pesagem de todas as vagens e grãos da parcela útil e divisão pelo número de plantas contidas da parcela útil), número e massa de grãos por vagem (a partir da separação dos grãos das vagens, realizando a contagem e pesagem dos grãos e dividindo pelo número de vagens contidas na parcela útil), a massa de 100 grãos e 100 vagens (determinada pela pesagem de 100 vagens e grãos), produtividade de vagens e de grãos (extrapolação dos resultados de massa de vagens e de grãos da área útil para $\mathrm{kg} \mathrm{ha}^{-1}$ ) e porcentagem de grãos não comerciais (a partir da relação entre a massa de grãos ruins e de grãos comerciais, sendo os dados expressos em porcentagem).

Os dados foram submetidos à análise de variância e os resultados referentes aos espaçamentos foram comparados pelo teste de Tukey a $5 \%$ de probabilidade quando significativos e os dados referentes à adubação foram submetidos à análise de regressão.

\section{Resultados e Discussão}

Observa-se na Tabela 1 que os valores de coeficiente de variação foram baixos $(<10 \%)$ e médios (10 a $20 \%$ ) para a maioria das variáveis (PINTO et al., 2017), sendo ideal para experimentos de campo, que estão sujeitos a vários fatores não controlados, principalmente os relacionados ao solo, que apresentam grande heterogeneidade, conforme relatado por Artur et al., (2014), ao verificarem que os atributos químicos do solo apresentaram grande variabilidade espacialmente.

Conforme os dados da Tabela 1, não ocorreram interações significativas entre os fatores para todas as variáveis analisadas, tornando possível a avaliação dos fatores separadamente por meio da média.

Tabela 1. Síntese da análise de variância, análise de regressão e do teste de médias para as variáveis população inicial, população final, altura da planta

\begin{tabular}{|c|c|c|c|c|c|c|}
\hline \multirow{2}{*}{ Fontes de Variação } & \multicolumn{2}{|c|}{ População Inicial } & \multicolumn{2}{|c|}{ População Final } & \multicolumn{2}{|c|}{ Altura } \\
\hline & Sequeiro & Gotejo & Sequeiro & Gotejo & Sequeiro & Gotejo \\
\hline & \multicolumn{6}{|c|}{ Valores de $\mathrm{F}$} \\
\hline Adubação (A) & $0,71^{\mathrm{NS}}$ & $0,51^{\mathrm{NS}}$ & $2,23^{\mathrm{NS}}$ & $1,18^{\mathrm{NS}}$ & $0,77^{\mathrm{NS}}$ & $3,63^{*}$ \\
\hline CV1 (\%) & 3,71 & 5,08 & 14,9 & 16,18 & 18,29 & 6,00 \\
\hline Espaçamento (E) & $1880 * *$ & $699 * *$ & $106 * *$ & $37,09 * *$ & $0,16^{\mathrm{NS}}$ & $1,40^{\mathrm{NS}}$ \\
\hline$A * E$ & $0,59^{\mathrm{NS}}$ & $2,57^{N S}$ & $0,29^{N S}$ & $0,40^{\mathrm{NS}}$ & $0,20^{\mathrm{NS}}$ & $0,46^{\mathrm{NS}}$ \\
\hline \multirow{2}{*}{ CV2 (\%) } & 4,09 & 6,22 & 15,9 & 26,81 & 8,18 & 10,26 \\
\hline & \multicolumn{6}{|c|}{ Análise de Regressão para Adubação } \\
\hline Linear & $0,34^{\mathrm{NS}}$ & $0,19^{\mathrm{NS}}$ & $1,55^{\text {NS }}$ & $1,51^{\mathrm{NS}}$ & $1,14^{\mathrm{NS}}$ & $1,21^{\mathrm{NS}}$ \\
\hline \multirow[t]{2}{*}{ Quadrática } & $0,43^{\mathrm{NS}}$ & $1,32^{\mathrm{NS}}$ & $4,98 *$ & $1,68^{\mathrm{NS}}$ & $0,18^{N S}$ & 3,47 * \\
\hline & \multicolumn{6}{|c|}{ Teste de Médias de Tukey $(p<0,05)$} \\
\hline Espaçamento & \multicolumn{4}{|c|}{----------- plantas ha ${ }^{-1}$--------- } & \multicolumn{2}{|c|}{----- cm ----- } \\
\hline 10 & 212499a & $202314 a$ & $182638 a$ & $164814 a$ & $31,5 a$ & $63,5 \mathrm{a}$ \\
\hline 20 & $111111 b$ & $111111 b$ & $100694 b$ & $90982 b$ & $30,7 a$ & $60,8 \mathrm{a}$ \\
\hline
\end{tabular}

Nota: Médias seguidas pela mesma letra minúscula na coluna não diferem entre si pelo teste de Tukey a $5 \%$ de probabilidade. ${ }^{* *}$ : significativo $(P<0,01)$; *: significativo $(P<0,05)$; CV\%: coeficiente de variação.

Para a adubação não ocorreu diferença significativa em todas as variáveis analisadas, exceto para a altura das plantas no sistema de gotejo que obteve significância $(P<0,05)$. Tais resultados diferem dos encontrados por Costa et al. (2017), que não obtiveram diferença 
significativa na altura das plantas entre os tratamentos com $500 \mathrm{~kg} \mathrm{ha}^{-1}$ da formulação 4-148 e o tratamento sem NPK, porém tais resultados podem estar relacionado ao uso de adubação nas culturas antecessoras, suprindo a necessidade da cultura do amendoim que é pouco responsiva a adubação em áreas adubadas anteriormente.

Nota-se na Tabela 1 que para o espaçamento entre as plantas, as populações inicial e final obtiveram diferença significativa $(P<0,01)$ nos sistemas de sequeiro e gotejo, ressaltando-se que o espaçamento de $10 \mathrm{~cm}$ obteve maiores populações inicial, final. Já para a altura não houve diferença significativa. Tais resultados podem ter ocorrido devido ao fato de a densidade não influenciar na altura das plantas quando as mesmas estão em condições ideais de clima e solo ou em casos onde ocorre restrição hídrica, limitando o crescimento das plantas independente da densidade (BARBIERI et al., 2017).

$\mathrm{Na}$ análise de regressão (Tabela 1) a população final no sistema de sequeiro obteve diferença significativa $(p<0,05)$ em função das doses de adubação, com modelo de regressão polinomial de segunda ordem, (Figura 2). Nota-se que o aumento das doses de adubação em semeadura proporcionou aumento da população, com ponto de máximo de 152.602 mil plantas ha 1 , aplicando-se $62,5 \%$ da dose recomendada de fósforo e potássio, após esse valor o excesso de adubo juntamente com a escassez de chuvas pode ter causado a morte das plantas menos resistentes.

Figura 2. Análise de regressão para a população final no sistema de sequeiro em função da dose de adubação.

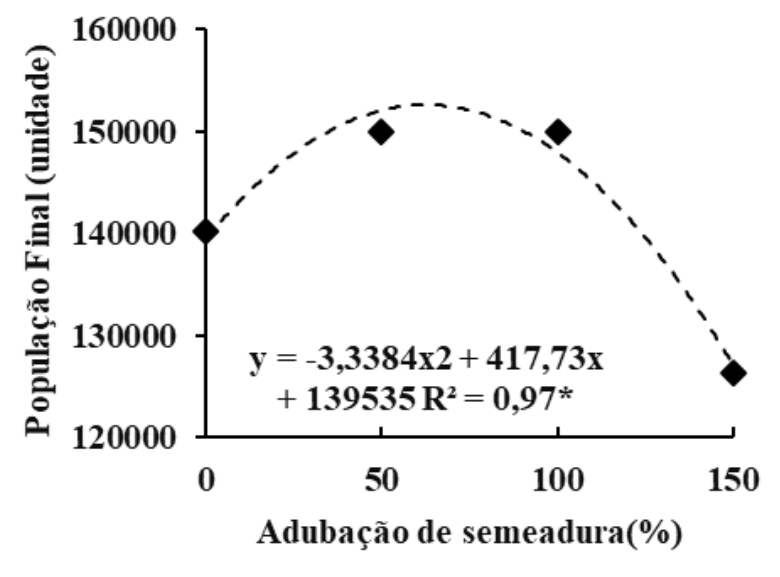

Tais resultados diferem dos observados por Costa et al. (2017) ao estudarem a resposta da cultivar BRS151L7 em função da adubação de semeadura, não obtendo diferença significativa para as populações inicial e final, porém com o experimento sendo conduzido sob irrigação, sistema no qual também não foi observado diferença significativa neste trabalho.
$\mathrm{Na}$ altura das plantas para o sistema de gotejo (Figura 3), o melhor modelo de regressão foi o polinomial de segunda ordem, significativo $(P<0,05)$, sendo o ponto de máximo de $63,95 \mathrm{~cm}$, aplicando-se $79,29 \%$ da dose recomendada. 
Figura 3. Análise de regressão para a altura no sistema de gotejo em função da dose de adubação.

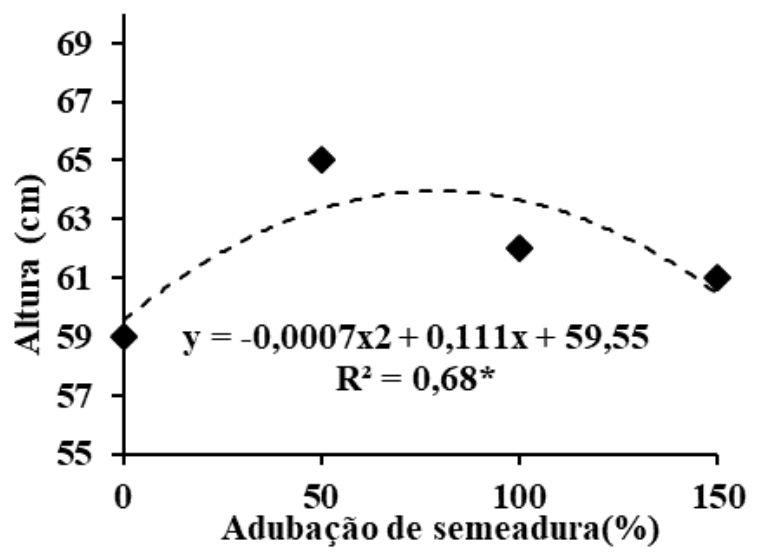

Resultados que diferem de Souza et al. (2012) ao avaliarem o desempenho do amendoim rasteiro em resposta à adubação fosfatada, obtiveram comportamento linear significativo para a altura das plantas, indicando que o amendoim responde a doses superiores às utilizadas, sendo que a maior dose $\left(200 \mathrm{~kg} \mathrm{ha}^{-1}\right)$ promoveu altura de $20,76 \mathrm{~cm}$, com este valor sendo bem inferior ao deste trabalho, por se tratar de amendoim rasteiro.
Verifica-se na Tabela 2 que o coeficiente de variação foi maior para estas variáveis, principalmente número e massa de vagens por planta, justamente por serem variáveis mais suscetíveis aos fatores não controlados, conforme encontrado por outros autores (SOUZA et al., 2012; COSTA et al. 2017; CAMARA et al., 2018).

Tabela 2. Síntese da análise de variância, análise de regressão e do teste de médias para as variáveis número de vagens por planta (NV/P), massa de vagens por planta (MV/P), massa de grãos por planta (MG/P).

\begin{tabular}{|c|c|c|c|c|c|c|}
\hline \multirow{2}{*}{ Fontes de Variação } & \multicolumn{2}{|c|}{$\mathrm{NV} / \mathrm{P}$} & \multicolumn{2}{|c|}{$\mathrm{MV} / \mathrm{P}$} & \multicolumn{2}{|c|}{$\mathrm{MG} / \mathrm{P}$} \\
\hline & Sequeiro & Gotejo & Sequeiro & Gotejo & Sequeiro & Gotejo \\
\hline & \multicolumn{6}{|c|}{ Valores de F } \\
\hline Adubação (A) & $1,92^{\mathrm{NS}}$ & $0,56^{\mathrm{NS}}$ & $4,26^{\mathrm{NS}}$ & $0,42^{\mathrm{NS}}$ & $0,72^{\mathrm{NS}}$ & $0,43^{\mathrm{NS}}$ \\
\hline CV1 (\%) & 25,35 & 35,44 & 18,87 & 39,01 & 62,72 & 32,35 \\
\hline Espaçamento $(\mathrm{E})$ & $27,09 * *$ & $5,49 *$ & $29,49 * *$ & $8,03^{*}$ & $2,25^{\mathrm{NS}}$ & $22,5 * *$ \\
\hline$A^{*} E$ & $1,96^{\mathrm{NS}}$ & $1,02^{\mathrm{NS}}$ & $1,03^{\mathrm{NS}}$ & $1,03^{\mathrm{NS}}$ & $0,46^{\mathrm{NS}}$ & $0,88^{\mathrm{NS}}$ \\
\hline \multirow[t]{2}{*}{ CV2 (\%) } & 27,81 & 37,62 & 25,25 & 34,56 & 76,06 & 25,28 \\
\hline & \multicolumn{6}{|c|}{ Análise de Regressão para Adubação } \\
\hline Linear & $2,54^{\mathrm{NS}}$ & $0,88^{\mathrm{NS}}$ & $6,65^{\mathrm{NS}}$ & $1,21^{\mathrm{NS}}$ & $0,17^{\mathrm{NS}}$ & $0,84^{\mathrm{NS}}$ \\
\hline \multirow[t]{2}{*}{ Quadrática } & $3,17^{\mathrm{NS}}$ & $0,64^{\mathrm{NS}}$ & $5,51^{\mathrm{NS}}$ & $0,05^{\mathrm{NS}}$ & $0,08^{\mathrm{NS}}$ & $0,31^{\mathrm{NS}}$ \\
\hline & \multicolumn{6}{|c|}{ Teste de Médias de Tukey $(p<0,05)$} \\
\hline Espaçamento & \multicolumn{2}{|c|}{-----unidade----- } & 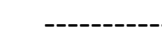 & ----------. & ----------- & ------ \\
\hline 10 & $7,71 b$ & $21,42 b$ & $6,33 b$ & $25,08 b$ & $1,58 a$ & $13,3 b$ \\
\hline 20 & $13,02 a$ & $29,33 a$ & $10,38 a$ & $35,60 a$ & $2,38 a$ & $20,5 a$ \\
\hline
\end{tabular}

Nota: Médias seguidas pela mesma letra minúscula na coluna não diferem entre si pelo teste de Tukey a $5 \%$ de probabilidade. ${ }^{* *}$ : significativo $(P<0,01)$; *: significativo $(P<0,05)$; CV\%: coeficiente de variação.

Para a adubação (Tabela 2), não foram verificadas diferenças significativas para as variáveis analisadas (Tabela 2), tais resultados podem está relacionado com o fato de antes da implantação do experimento na área experimental ter ocorrido o cultivo de sorgo sacarino que requer maiores doses de nutrientes, desse modo o resíduo presente no solo pode ter 
suprido as necessidades da cultura de amendoim. Porem Costa et al. (2017), que não observaram diferença significativa no número de vagens por planta, para os tratamentos com e sem NPK na semeadura.

Observa-se na Tabela 2 que no fator espaçamento, o número de vagens por planta e a massa de vagens por planta no sistema de sequeiro obtiveram diferença significativa $(p<0,01)$, enquanto que no sistema de gotejo, ambas diferiram $(p<0,05)$, evidenciando que 0 espaçamento de $20 \mathrm{~cm}$ obteve maior número e massa de vagens por planta, tanto no sistema de sequeiro quanto no com irrigação complementar.

Verifica-se que a massa de grãos por planta no sistema de gotejo (Tabela 2), obteve diferença significativa $(P<0,01)$, para o fator espaçamento. Evidenciando que o espaçamento de $20 \mathrm{~cm}$ obteve aumento de $54 \%$ na massa de grãos por planta. Tais resultados podem ter ocorrido devido ao fato de o maior espaçamento apresentar menor competição interespecífica por conta da menor densidade populacional, permitindo melhor aproveitamento de luz, água e nutrientes (CAMARA et al., 2018). Enquanto no sequeiro, a densidade de plantas não teve efeito, pois o principal fator limitante pode ter sido a deficiência hídrica, reduzindo o enchimento e a massa dos grãos, independente do espaçamento entre as plantas.

$\mathrm{Na}$ Tabela 3 nota-se que $\mathrm{o}$ fator espaçamento foi o que apresentou maiores coeficientes de variação em relação à adução obtendo maior efeito nas variáveis analisadas.

Tabela 3. Síntese da análise de variância, análise de regressão e do teste de médias para as variáveis Massa de grãos por vagens (MG/V), massa de mil grãos (M1000G) e massa de 100 vagens (M100V).

\begin{tabular}{|c|c|c|c|c|c|c|}
\hline \multirow{2}{*}{ Fontes de Variação } & \multicolumn{2}{|c|}{ MG/V } & \multicolumn{2}{|c|}{ M1000G } & \multicolumn{2}{|c|}{ M100V } \\
\hline & Sequeiro & Gotejo & Sequeiro & Gotejo & Sequeiro & Gotejo \\
\hline & \multicolumn{6}{|c|}{ Valores de F } \\
\hline Adubação (A) & $0,53^{\mathrm{NS}}$ & $1,56^{\mathrm{NS}}$ & $0,79^{\mathrm{NS}}$ & $0,07^{\mathrm{NS}}$ & $0,41^{\mathrm{NS}}$ & $1,70^{\mathrm{NS}}$ \\
\hline CV1 (\%) & 70,28 & 18,43 & 119,2 & 10,07 & 23,43 & 10,20 \\
\hline Espaçamento (E) & $0,07^{\mathrm{NS}}$ & $2,80^{\mathrm{NS}}$ & $1,03^{\mathrm{NS}}$ & $0,02^{\mathrm{NS}}$ & $0,08^{\mathrm{NS}}$ & $3,36^{\mathrm{NS}}$ \\
\hline$A^{*} E$ & $0,67^{\mathrm{NS}}$ & $2,02^{\mathrm{NS}}$ & $0,94^{\mathrm{NS}}$ & $0,77^{\mathrm{NS}}$ & $0,53^{\mathrm{NS}}$ & $1,77^{\mathrm{NS}}$ \\
\hline \multirow[t]{2}{*}{ CV2 (\%) } & 74,65 & 13,10 & 122,6 & 12,34 & 21,15 & 5,90 \\
\hline & \multicolumn{6}{|c|}{ Análise de Regressão para Adubação } \\
\hline Linear & $0,14^{\mathrm{NS}}$ & $0,01^{\mathrm{NS}}$ & $1,66^{\mathrm{NS}}$ & $0,14^{\mathrm{NS}}$ & $0,74^{\mathrm{NS}}$ & $0,56^{\mathrm{NS}}$ \\
\hline \multirow[t]{2}{*}{ Quadrática } & $0,04^{\mathrm{NS}}$ & $4,64^{\mathrm{NS}}$ & $0,66^{\mathrm{NS}}$ & $0,92^{\mathrm{NS}}$ & $0,23^{\mathrm{NS}}$ & $0,72^{\mathrm{NS}}$ \\
\hline & \multicolumn{6}{|c|}{ Teste de Médias de Tukey $(p<0,05)$} \\
\hline Espaçamento & \multicolumn{6}{|c|}{ 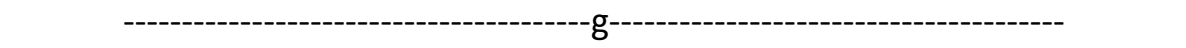 } \\
\hline 10 & $0,20 \mathrm{a}$ & $0,65 a$ & 770a & $590 a$ & $82,0 a$ & $117 a$ \\
\hline 20 & $0,22 \mathrm{a}$ & $0,70 \mathrm{a}$ & $491 \mathrm{a}$ & $595 a$ & $83,9 a$ & $121 \mathrm{a}$ \\
\hline
\end{tabular}

Nota: Médias seguidas pela mesma letra minúscula na coluna não diferem entre si pelo teste de Tukey a $5 \%$ de probabilidade. ${ }^{* *}$ : significativo $(\mathrm{P}<0,01)$; $^{*}$ : significativo $(\mathrm{P}<0,05)$; $\mathrm{CV} \%$ : coeficiente de variação. Fonte: autor

No fator adubação e espaçamento (Tabela 3) não ocorreu diferença significativa para todas as variáveis analisadas. Tais resultados diferem dos observados por Souza et al. (2012) ao estudarem o efeito das doses de fósforo, que obtiveram diferença significativa a $5 \%$ na massa de 100 grãos com o aumento das doses de fósforo $\left(50,100\right.$ e $200 \mathrm{~kg}$ ha ${ }^{-1}$ de $\left.\mathrm{P}_{2} \mathrm{O}_{5}\right)$ proporcionando acréscimo de $5 \%$ para a maior dose estudada em relação à não aplicação do fósforo.

Observa-se na Tabela 4 que para o fator adubação não houve diferença significativa para todas as variáveis. Resultado semelhante aos de
Meneghette et al. (2017) ao estudarem a resposta do amendoim submetido a diferentes doses de fósforo e potássio, não verificaram significância com a aplicação de três doses de adubo fosfatado $\left(0,60\right.$ e $120 \mathrm{~kg}^{-1}$ de $\left.^{\mathrm{P}_{2} \mathrm{O}_{5}}\right)$ e de adubo potássico $\left(0,20\right.$ e $40 \mathrm{~kg} \mathrm{ha}^{-1}$ de $\left.\mathrm{K}_{2} \mathrm{O}\right)$.

Com relação ao fator espaçamento, a produtividade de vagens no sistema de gotejo (Tabela 4) foi a única variável com diferença significativa a $(P<0,05)$. Ressaltando-se que $o$ espaçamento de $10 \mathrm{~cm}$ proporcionou aumento de $16,6 \%$ na de produtividade de vagens. Resultados que corroboram com Peixoto et al. (2008), ao estudarem as características 
agronômicas e a produtividade de amendoim em diferentes arranjos espaciais, observaram que a redução do espaçamento entre plantas de 20 para $10 \mathrm{~cm}$ proporcionou aumento significativo $(P<0,05)$ na produtividade de vagens e de grãos.

Tabela 4. Síntese da análise de variância, análise de regressão e do teste de médias para as variáveis Produtividade de vagens (PV), Produtividade de grãos (PG) e grãos não comerciais (GNC)

\begin{tabular}{|c|c|c|c|c|c|c|}
\hline \multirow{2}{*}{ Fontes de Variação } & \multicolumn{2}{|c|}{ PV } & \multicolumn{2}{|c|}{ PG } & \multicolumn{2}{|c|}{ GNC } \\
\hline & Sequeiro & Gotejo & Sequeiro & Gotejo & Sequeiro & Gotejo \\
\hline & \multicolumn{6}{|c|}{ Valores de $\mathrm{F}$} \\
\hline Adubação (A) & $0,31^{\mathrm{NS}}$ & $0,74^{\mathrm{NS}}$ & $0,26^{\mathrm{NS}}$ & $2,12^{\mathrm{NS}}$ & $0,93^{\mathrm{NS}}$ & $1,12^{\mathrm{NS}}$ \\
\hline CV1 (\%) & 19,61 & 18,92 & 60,73 & 19,27 & 35,46 & 38,4 \\
\hline Espaçamento (E) & $1,32^{\mathrm{NS}}$ & $9,29 *$ & $0,30^{\mathrm{NS}}$ & $2,08^{\mathrm{NS}}$ & $0,37^{\mathrm{NS}}$ & $0,35^{\mathrm{NS}}$ \\
\hline$A * E$ & $0,77^{\mathrm{NS}}$ & $0,20^{\mathrm{NS}}$ & $0,63^{\mathrm{NS}}$ & $0,30^{\mathrm{NS}}$ & $1,56^{\mathrm{NS}}$ & $0,68^{\mathrm{NS}}$ \\
\hline \multirow[t]{2}{*}{ CV2 (\%) } & 22,24 & 14,29 & 67,12 & 20,59 & 51,69 & 51,4 \\
\hline & \multicolumn{6}{|c|}{ Análise de Regressão para Adubação } \\
\hline Linear & $0,85^{\mathrm{NS}}$ & $0,22^{\mathrm{NS}}$ & $0,04^{\mathrm{NS}}$ & $0,04^{\mathrm{NS}}$ & $0,04^{\mathrm{NS}}$ & $0,00^{\mathrm{NS}}$ \\
\hline \multirow[t]{2}{*}{ Quadrática } & $0,06^{\mathrm{NS}}$ & $1,87^{\mathrm{NS}}$ & $0,01^{\mathrm{NS}}$ & $5,86^{*}$ & $0,19^{\mathrm{NS}}$ & $0,13^{\mathrm{NS}}$ \\
\hline & \multicolumn{6}{|c|}{ Teste de Médias de Tukey $(p<0,05)$} \\
\hline Espaçamento & \multicolumn{4}{|c|}{ 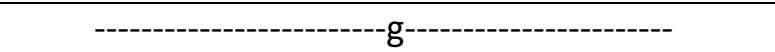 } & \multicolumn{2}{|c|}{-----------\%---------- } \\
\hline 10 & $1139 a$ & $3720 a$ & $273 a$ & $1842 a$ & $32,7 a$ & $12,69 a$ \\
\hline 20 & $1041 a$ & $3188 b$ & 239a & $2047 a$ & $36,7 a$ & $11,38 \mathrm{a}$ \\
\hline
\end{tabular}

Nota: Médias seguidas pela mesma letra minúscula na coluna não diferem entre si pelo teste de Tukey a $5 \%$ de probabilidade.**: significativo $(P<0,01)$; *: significativo $(P<0,05)$; $C V \%$ : coeficiente de variação. Fonte: autor

Verifica-se na Tabela 4 que na produtividade de grãos no sistema de gotejo, a análise de regressão foi significativa a $5 \%$ para o modelo de regressão polinomial, com o aumento das doses de adubação em semeadura elevando a produtividade (Figura 4), sendo o ponto de máximo com $2.145 \mathrm{~kg} \mathrm{ha}^{-1}$ de grãos, aplicando-se $77 \%$ da dose recomendada. O efeito positivo do PK sobre a produtividade de grãos pode estar condicionado às várias funções que estes nutrientes exercem no metabolismo vegetal, atuando na síntese de proteínas, respiração e fotossíntese como ativadores de enzimas e outras funções, contribuído diretamente com o aumento da produtividade (CORREIA et al., 2012).

Figura 4. Análise de regressão para a produtividade de grão no gotejamento em função da dose de adubação.

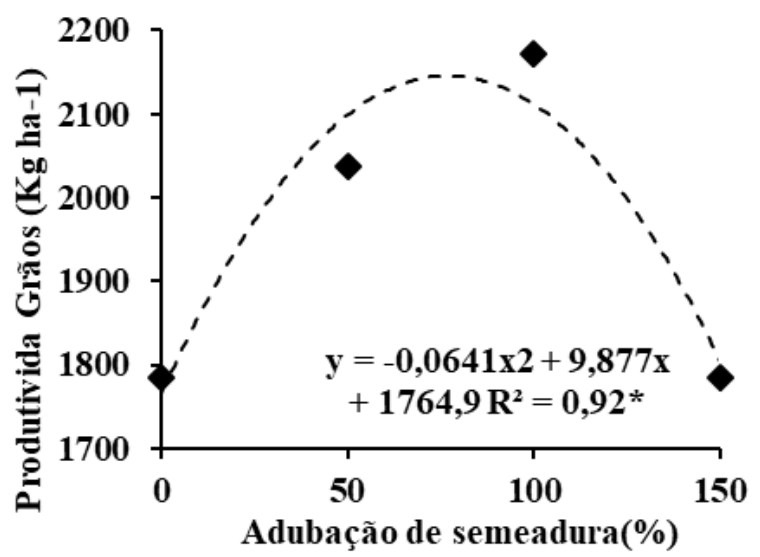


Santos et al. (2010) ao avaliarem o efeito da aplicação de diferentes doses de fosforo e nitrogênio no rendimento do amendoim, observaram resposta significativa com acréscimo de $61 \%$ na produtividade de grãos para a adubação fosfatada em relação aos tratamentos sem adubação.

No presente estudo, observa-se que o sistema de gotejo apresentou aumento em média de $50 \%$ quando comparado ao sistema de sequeiro nas variáveis altura e massa de plantas, número e massa de vagens por planta. Enquanto para a produtividade de vagens e grãos 0 aumento foi superior a $50 \%$, além disso, promoveu redução da porcentagem de grãos não comerciais, ficando evidente a necessidade hídrica da cultura, em especial para essas variáveis que possuem relação direta com a disponibilidade hídrica da planta.

No ano agrícola do presente estudo, a irrigação complementar por gotejo teve grande efeito, principalmente em virtude das baixas precipitações ocorridas $(296 \mathrm{~mm})$ e da distribuição irregular (Figura 1). Segundo Barbieri et al. (2017), a cultura exige precipitação de 700 $\mathrm{mm}$ para seu desenvolvimento. Portanto, este déficit de $404 \mathrm{~mm}$ prejudicou o desenvolvimento e produtividade da cultura.

\section{Conclusão}

A aplicação de $80 \%$ da dose recomendada de fósforo e potássio é suficiente para suprir a necessidade da cultura em condições hídricas ideais para a desenvolvimento da cultura.

O espaçamento de $20 \mathrm{~cm}$ entre plantas é mais recomendado para a cultura do amendoim, proporcionando maior número de vagens por planta, massa de vagens por planta e massa de grãos por planta.

O uso de irrigação complementar em anos com baixa precipitação atmosférica foi excelente alternativa para elevar a produtividade de vagens em $198 \%$ e de grãos da cultura do amendoim em $660 \%$.

Para de terminar a dose ideal de adubação em semeadura no cultivo de amendoim em sistema de sequeiro e necessário mais estudos com precipitação capaz de suprir a necessidade da cultura durante o ciclo.

\section{Referências}

ARTUR, A. G.; OLIVEIRA, D. P.; COSTA, M. C. G.; ROMERO, R. E.; SILVA, M. V. C.; FERREIRA, T. O. Variabilidade espacial dos atributos químicos do solo, associada ao microrrelevo. Revista Brasileira de Engenharia Agrícola e Ambiental, Campina Grande, v. 18, n. 2, p. 141-149, 2014. https://doi.org/10.1590/S141543662014000200003

BARBIERI, D. J.; DALLACORT, R.; FARIA JUNIOR, C. A.; FREITAS, P. S. L.; CARVALHO, M. A. C. Peanut cultivars submitted to irrigation levels and nitrogen adubation in tropical climate. Engenharia Agrícola, Jaboticabal, v. 37, n. 6, p. 1126-1136, 2017. https://doi.org/10.1590/18094430-eng.agric.v37n6p1126-1136/2017

BRASIL. EMBRAPA. Sistema de produção de amendoim: fertilidade do solo e adubação. Brasília, DF: Embrapa, 2014. (Embrapa algodão. Documentos, 7). Disponível em: https://www.spo.cnptia.embrapa.br/conteudo?p _p_lifecycle $=0 \& p \_p \_i d=$ conteudoportlet_WAR_ sistemasdeproducaolf6_1ga1ceportlet\&p_p_col_ count=1\&p_p_col_id=column-\&p_p_state=nor mal\&p

76293187_sistemaProducaold $=3803 \&$ p_r_p_996514994_topicold=3432\&p_p_ mode=view. Acesso em: 18 jan. 2017.

CAMARA, F. T.; MOTA, A. M. D.; NICOLAU, F. E. A.; PINTO, A. A.; SILVA, J. M. F. Produtividade de feijão caupi crioulo em função do espaçamento entre linhas e número de plantas por cova. Revista de Agricultura Neotropical, Cassilândia, v. 5, n. 2, p. 19-24, 2018.

https://doi.org/10.32404/rean.v5i2.2282

CORREIA, M. A. R.; PRADO, R. M.; FIRMATO ALMEIDA, T. B. F.; PUGA, A. P.; BARBOSA, J. C. Avaliação da desordem nutricional de plantas de amendoim cultivadas em solução nutritiva suprimidas de macronutrientes. Scientia Agraria, Curitiba, v. 13, n. 1, p. 21-28, 2012. https://doi.org/10.5380/rsa.v13i1.40857

COSTA, T. B.; SILVA, F. E.; PENHA FILHO; N.; LOPES, N. S.; CAMARA, F. T. Resposta à adubação de duas cultivares de amendoim em dois sistemas de semeadura. Agrarian Academy, Goiânia, v. 4, n. 8, p. 240-248, 2017. 
https://doi.org/10.18677/Agrarian Academy 20 $\underline{17 b 25}$

COMPANHIA NACIONAL DE ABASTECIMENTO (CONAB). Acompanhamento da safra brasileira de grãos. Brasília, DF: CONAB, 2017. Disponível em:

http://www.conab.gov.br/OlalaCMS/uploads/arq uivos/1708_10_11_27

_12_boletim_graos_agosto_2017.pdf. Acesso em: 23 ago. 2017.

DIAS, M. S.; REIS, L. S.; LIMA, I. R. V.; OLIVEIRA, A. W.; SANTOS, R. H. S.; ALMEIDA, C. A. C.; SILVA, V. M. Eficiência do uso da água pela cultura do amendoim sob diferentes lâminas de irrigação e adubação. Colloquium Agrariae, Presidente Prudente-SP, v. 2, n. 15, p. 72-83, 2019.

https://doi.org/10.5747/ca.2019.v15.n1.a286

HEID, D. M.; ZÁRATE, N. A. H.; OHLAND, R. A. A.; TORALES, E. P.; MORENO, L. B.; VIEIRA, M. C. Produtividade agronômica de genótipos de amendoim Virginia cultivados com diferentes espaçamentos entre fileiras no canteiro. Revista de Ciências Agrárias, Recife, v. 39, n. 1, p. 105113, 2016. https://doi.org/10.19084/RCA15058

MENEGHETTE, H. H. A.; LAZARINI, E.; BOSSOLANI, J. W.; PARRA, L. F.; HAYASHI, F. K. Doses de fósforo e potássio em plantas de amendoim na presença e ausência de adubação foliar. Revista Brasileira de Engenharia de Biossistemas, Tupã, v. 11, n. 2, p. 125-134, 2017.

https://doi.org/10.18011/bioeng2017v11n2p125$\underline{134}$

PEIXOTO, C. P.; GONÇALVES, J. A.; PEIXOTO, M. F. S. P.; CARMO, D. O. Características agronômicas e produtividade de amendoim em diferentes espaçamentos e épocas de semeadura no recôncavo baiano. Bragantia, Campinas, v. 67, n. 3, p. 673-684, 2008.

https://doi.org/10.1590/S0006-

$\underline{87052008000300016}$

SANTOS, A. R.; SILVA, P. C. C.; COUTO, J. L.; SOUZA, G. S.; LOBO, D. M. Rendimento e nutrição do amendoinzeiro em função da interação PxN em latossolo amarelo. Revista da Faculdade de Zootecnia, Veterinária e Agronomia, Uruguaiana, v. 17, n. 2, p. 233-248, 2010.
SILVA, J. M. F.; DUTRA, A. S.; CAMARA, F. T.; PINTO, A. A.; SILVA, F. E. Row spacing, plant density, sowing and harvest times for sweet sorghum. Pesquisa Agropecuária Tropical, v. 47, n. 4, p. 408-415, 2017.

https://doi.org/10.1590/198340632017v4748585

SOUSA, G. G.; AZEVEDO, B. M.; OLIVEIRA, J. R. R.; MESQUITA, T. O.; VIANA, T. V. A. Ó, L. M. G. Adubação potássica aplicada por fertirrigação e pelo método convencional na cultura do amendoim. Revista Brasileira de Engenharia Agrícola e Ambiental, Campina Grande, v. 17, n. 10, p. 1055-1060, 2013.

https://doi.org/10.1590/S1415-

$\underline{43662013001000005}$

SOUZA, U. O.; SANTOS, L. G.; CARVALHO, G. B.; SANTOS, A. R.; SOUZA, G. S. Adubação fosfatada e qualidade de luz modificada no desenvolvimento e produtividade da cultura do amendoim. Enciclopédia Biosfera, Goiânia, v. 8, n. 15, p. 1635, 2012.

PINTO, A. A.; SANTANA, L. D.; DAMACENO, Y. R. P.; SANTOS. S. L. L.; CAMARA, F. T. Produção de espigas verdes por diferentes cultivares comerciais de milho em função da adubação NPK de semeadura. Revista Brasileira de Milho e Sorgo, v. 16, n. 3, p. 414-425, 2017.

https://doi.org/10.18512/19806477/rbms.v16n3p414-425 